\title{
Investigation and analysis on the current situation of rural housing in the cold area under the background of "beautiful countryside"
}

\author{
LEI ZHANG \\ CHANGCHUN UNIVERSITY OF ARCHITECTURE AND CIVIL ENGINEERING \\ Jilin Province CHINA
}

\begin{abstract}
Rural housing is the main content of rural construction. Accelerating rural development and building "Beautiful Countryside" is a major task of the country. In this paper, taking a village in a cold area as an example, the existing problems of overall planning, architectural design, building energy saving, energy utilization are analyzed, which provides the basis and reference for solving the common problems in this area.
\end{abstract}

\section{Introduction}

In recent years, the country attaches great importance to rural construction and development, and building the new socialist countryside has become a major historical task. Since the Fifth Plenary Session of the 16th Central Committee of the Communist Party of China in 2005 put forward the specific requirements of "production development, well-off life, rural civilization, clean village appearance and democratic management", many provinces and cities in the country have successively formulated the "Beautiful Countryside" construction plan. "Guangfa Village, Gongpengzi Town, Fuyu City, Songyuan City, Jilin Province" in the cold area has become a typical model of "comprehensive social governance"; "Dahuangdi Village, Changyi District, Jilin City, Jilin Province" was rated as the most beautiful characteristic residential village in China in 2014; "Hongqi Village, Antu County, Jilin Province" was rated as the characteristic folk village; "Chenjiadian Village, Nongan County, Jilin Province" was rated as the modern new village. ${ }^{[1]}$

Under the correct guidance of national policies, the construction of rural housing in severe cold areas has changed significantly, but it has not been fully promoted. Some areas started late and the changes took effect slowly. The lack of scientific overall planning and blind construction result in a lack of connotation rooted in the region and culture, forming a homogeneous layout. In the aspect of building energy saving, more research needs to be carried out. Academician Jiang Yi, director of the center for building energy saving research of Tsinghua University, put forward that "there is serious air pollution in the north of China, so reducing the external dependence of energy, reducing carbon emissions, and effectively controlling air pollution are urgent problems in the field of energy". ${ }^{[2]}$
Academician Jiang pointed out that the theme of building energy saving academic week of Tsinghua University in 2020 is rural building energy saving. ${ }^{[3]}$ Therefore, it is a key factor for the development of "Beautiful Countryside" to build rural houses which are suitable for the local residents and can save energy.

\section{Current situation of rural housing in severe cold area}

\subsection{Overall planning of villages and towns}

There is a lack of overall planning in villages and towns. The cultivated land is generally set at the entrance of the village, and the houses are arranged inside the village. The roads inside the villages and towns are narrow. In some places, there is only one stream of traffic is available. Most of the houses are self-built, without considering the surrounding environment. The overall layout of the building is lack of uniformity, the spacing does not meet the residential planning standards of villages and towns, and the courtyard walls with equal height of the residential buildings near the street are painted with colored drawing or pattern, with a lack of cultural deposits and performance that can reflect the local characteristics.

\subsection{Residential courtyard planning}

The rural houses generally cover a large area, each of which has its own courtyard. The entrance of the courtyard is often used as a vegetable garden or firewood stacking place. The building is located in the back and middle position, which is usually composed of three houses in a semi-enclosed form, with the main building in the middle and the warehouses on both sides. Behind the building, it is the backyard, which serves as a septic tank, garbage 
dump, etc. Some residential entrances are located between buildings and courtyards according to the road location. The diligence of each family determines whether it is clean or not. The overall effect of village appearance is average. Relevant technical standard system lags, without overall planning and design.

\subsection{Residential form and layout}

\subsubsection{Residential form}

The layout of rural housing is relatively simple. Taking a village in severe cold area as an example, the forms are mainly divided into two types: adobe houses and brick houses. The number of adobe houses is relatively small, most of which were built decades ago, which are seriously dilapidated, many of which have collapsed, and the existing ones have been built several times; the number of brick houses is relatively large, most of which were built around 2010, the construction methods of which are divided into self-built and state funded "poverty alleviation houses" which are mostly built in 2016-2018. (see Figure 1 for the proportion).

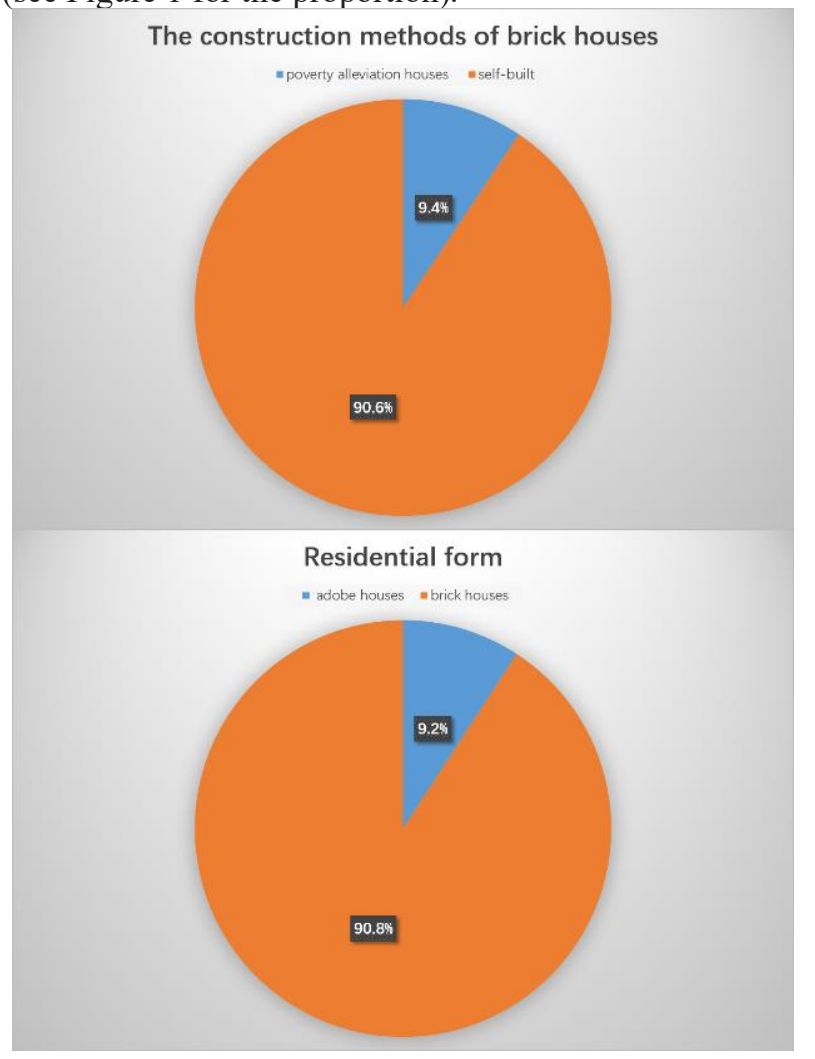

Figure 1 Residential form statistics of a village drawn by the author

\subsubsection{Residential layout}

The plane layout of the adobe houses is single, covering an area of about 80 square meters. The living function is mixed, lacking privacy, with poor sanitary conditions, poor ventilation effect in summer and no heat preservation on the wall. The main heating is the heated brick bed and hot wall, and the indoor thermal comfort in winter is not good. This type of housing is in the phase of being eliminated (see Figure 2). The plane layout of the self-built brick houses is relatively improved, covering an area of about 100 square meters, with clear function divisions, good ventilation effect, thermal insulation of the peripheral protective structure, and the use of "beibao" and "kuaer" to achieve the effect of cold protection. In winter, the heating is mainly based on radiators and heated brick bed, with good thermal comfort in the daytime and poor at night. The facade is simple in form, with two sloped tile roofs and ceramic tile walls as the main forms of expression, lacking regional characteristics and all in the same key (see Figure 3 and Figure 4). "Poverty alleviation housing" mainly has two types of area layout: 40 square meters and 60 square meters. There is $370 \mathrm{~mm}$ wall with insulation layer. The function layout is single, with living and catering function to meet the basic needs of farmers; the introduction of water equipment is convenient for farmers to drink (see Figure 5).

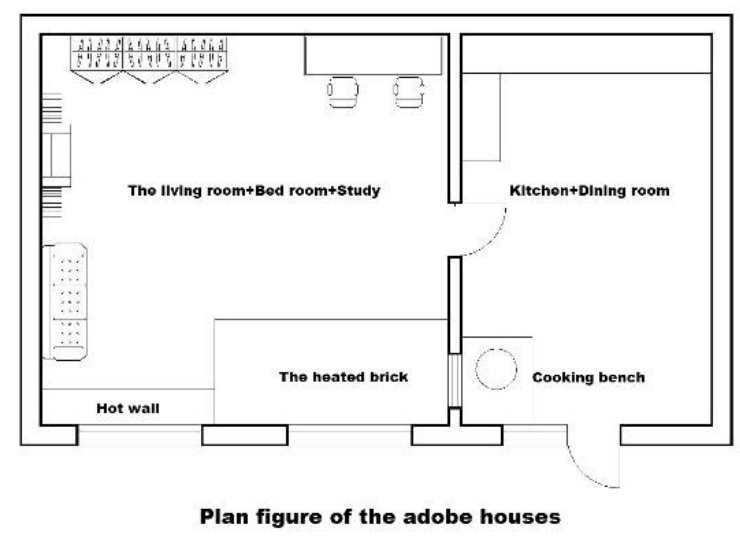

Figure 2 Plan figure of the adobe houses in a village drawn by the author Figure

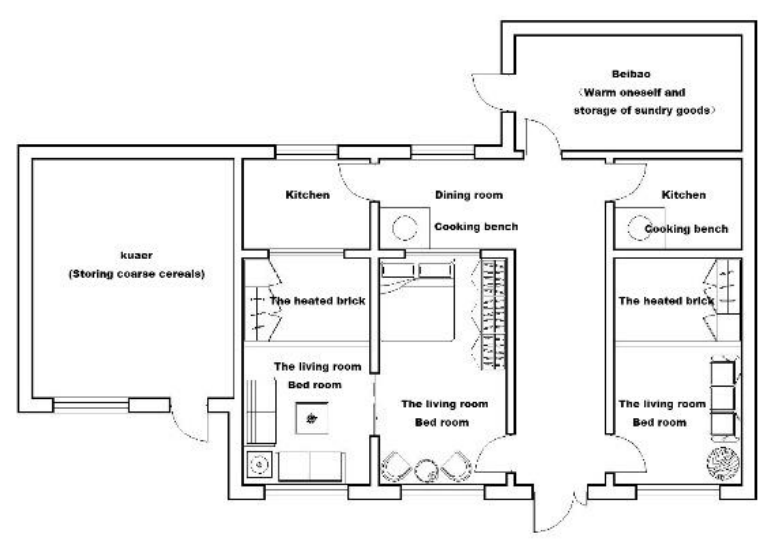

Plan figure of the brick houses

Figure 3 Plan figure of the brick houses in a village drawn by the author 


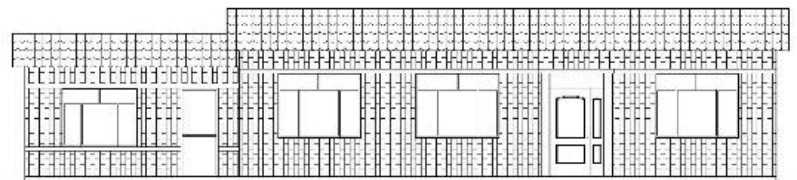

Elevation of the brick houses

Figure 4 Elevation of the brick houses in a village drawn by the author

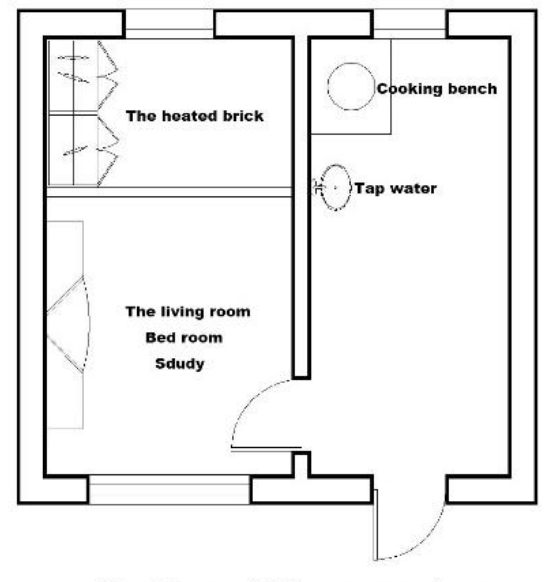

Plan figure of $\mathbf{4 0}$ square meters

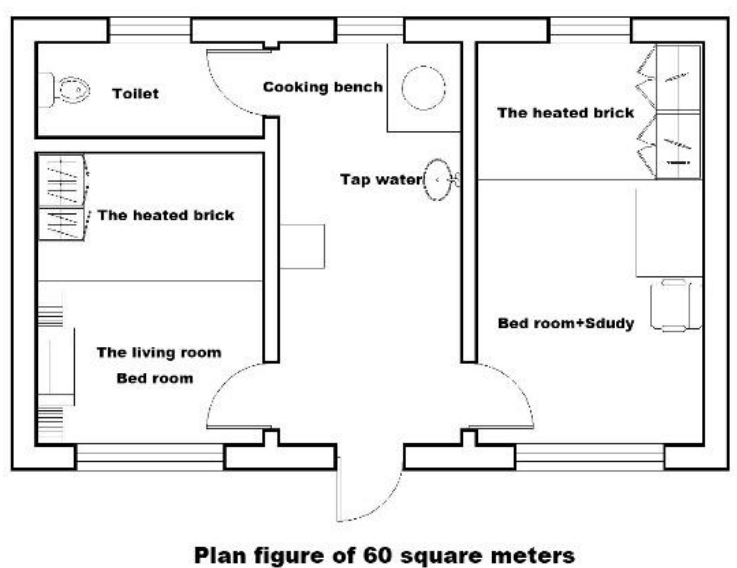

Figure 5 Plan figure of the "poverty alleviation houses" in a village drawn by the author

\subsection{Building energy saving and new energy utilization}

Based on the above data analysis, rural houses in severe cold area mostly adopt self-finance and self-built mode, imitating traditional experience and personal preference, lacking professional guidance in layout, modeling and energy saving, excessively pursuing the large covered area without limitation, with large building shape coefficient. In severe cold area, the winter is cold and the heating time is long. Because of the nonstandard construction, the energy consumption in winter is high, the temperature difference between day and night is large, and the thermal comfort is not good. (see Figure 6 for 24-hour temperature change). It can be seen from the figure that the maximum indoor temperature in winter is about $22{ }^{\circ} \mathrm{C}$ in the daytime. When the heating stops at night, it will reduce by 1.5-2.0
${ }^{\circ} \mathrm{C}$ every hour. At about four o'clock in the morning, it will decrease to a minimum of $7{ }^{\circ} \mathrm{C}$. After the heating starts, it will increase by $3 \cdot 0-5.0^{\circ} \mathrm{C}$ every hour until it reaches 22 ${ }^{\circ} \mathrm{C}$. At night, the indoor temperature is low, and the living comfort of farmers is poor.

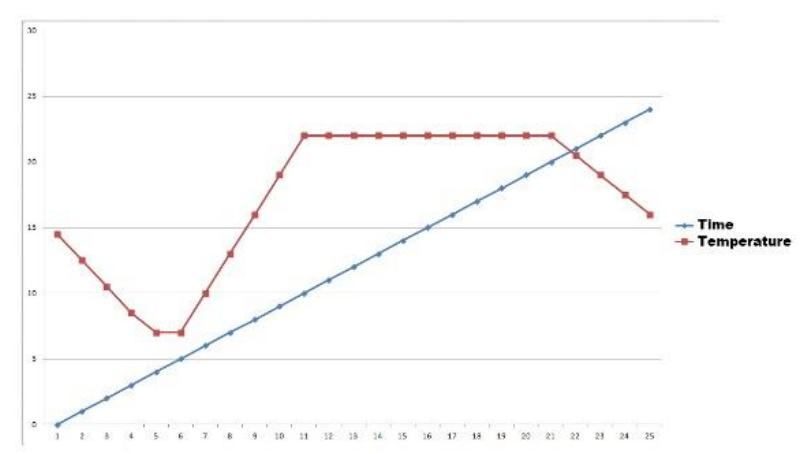

Figure 6 24-hour temperature change

In recent years, heat preservation has been set up in the outer envelope of newly-built rural houses. There is $370 \mathrm{~mm}$ thick brick wall with EPS thin plastering outer insulation. This form of heat preservation has low cost and good thermal performance, which has been widely promoted in villages and towns. Double glass plastic steel windows with good air tightness are used for doors and windows. The roof adopts the inverted thermal insulation roof, and the ground is basically not provided with thermal insulation measures, resulting in the ground moist and large heat dissipation.

The heating mode of villages and towns in severe cold area is mainly coal burning, which wastes energy and causes environmental pollution, which is not conducive to the construction of "Beautiful Countryside" with "blue sky, clear water, suitable for living and business". Clean heating of villages and towns in severe cold area is an important part of China's energy revolution in the future. It is of great significance to form new energy sources by developing biomass energy and renewable energy to replace fossil energy. At present, using corn straw to make solid compressed particles as fuel has been carried out in Northeast China, and it has become a new biomass energy. The output of corn is large in Northeast China, so it is very important to make full use of its waste in order to prevent farmers from burning at will and causing air pollution.

\section{Conclusion}

Promoting ecological civilization and building "Beautiful Countryside" are the key construction contents of the state. The development of rural housing in severe cold area is relatively slow due to the special climate environment and economic constraints, which requires in-depth research and exploration in the aspects of overall planning, architectural design, building energy saving, technical conditions, energy utilization, etc. In this paper, through the analysis of the problems in the residential design of a village in the cold area, it provides a reference for seeking solutions based on the local cultural background and climate characteristics. 


\section{References}

1. In 2014, the most beautiful leisure village in China was announced. China Agricultural News Network

2. Special topic of Jiang Yi / Thoughts on energy revolution by academician Jiang $Y i$

3. Interview / Jiang Yi's new idea of building energy saving in the victory of "war" and "epidemic"

4. Yaolong Zhang,Yani Wang, Miaomiao Shi Research on new rural housing design under the background of beautiful rural construction Architectural Design Management (2016.10.25)

5. Fei Li, Yuhang Hao, Analysis of Technical and Economic Benefits of Energy Saving for Rural Residential Buildings in Cold Areas Fly Ash Comprehensive Utilization (2017.6.25)

6. Hong Jin, Teng Shao Research on Energy-saving Optimization Design of Rural Residential Buildings in Severe Cold Areas Architectural Journal (2015.12.31) 